\title{
The Influence of Perceived Stress on various dimensions of Well Being
}

\author{
Pooja Soni ${ }^{1}$, Gautam Gawali \\ ${ }^{1}$ Assistant Professor, Department of Psychology, K.C. College, Mumbai, and Research Scholar, \\ Department of Applied Psychology and Counseling Center, University of Mumbai. \\ ${ }^{2}$ Professor and Head, Department of Applied Psychology and Counseling Centre, University of Mumbai. \\ E-mail - poojajosh@gmail.com \\ Corresponding Author - Pooja Soni
}

\begin{abstract}
Background: There is ample research evidence that stress affects one's well-being. The present study seeks to understand which aspects of well-being get affected by various levels of perceived stress.

Methodology: College students in the age range of 18-22 years participated in the study. They were given 'Perceived Stress Scale' to measure their perceived stress levels and Ryff's 'Psychological Well-being Scale' to measure their psychological well-being. One way ANOVA was calculated to serve the objective of the study.

Results: The analysis revealed that as expected there was a significant difference in psychological wellbeing as a function of level of perceived stress. $\left[\mathrm{F}_{(2,102)}=15.27, \mathrm{p}<0.001\right]$. There was a significant difference in only four of the six dimensions of psychological well-being namely self-acceptance $\left[\mathrm{F}_{(2,102)}=5.63\right.$, $\mathrm{p}<0.005]$, environmental mastery $\left[\mathrm{F}_{(2,102)}=21.58, \mathrm{p}<0.001\right]$, autonomy $\left[\mathrm{F}_{(2,102)}=8.37, \mathrm{p}<0.001\right]$ and positive relations with others $\left[\mathrm{F}_{(2,102)}=3.99, \mathrm{p}<0.02\right]$ as a function of low, moderate or high level of perceived stress. There was no significant influence of perceived stress on 'purpose in life' $\left[F_{(2,102)}=0.34\right.$, NS] and 'personal growth' $\left[\mathrm{F}_{(2,102)}=2.73, \mathrm{~ns}\right]$ dimensions of well-being.

Conclusion: Perceived stress may affect certain dimensions of well being. The implications of the study findings for positive youth development are discussed and implied.
\end{abstract}

Key words: perceived stress, well being, students, self acceptance, autonomy, stress, purpose in life.

(Paper received $-10^{\text {th }}$ October 2017, Peer review completed $-24^{\text {th }}$ October 2017)

(Accepted $-26^{\text {th }}$ October 2017)

\section{INTRODUCTION}

Although we experience stress all the time, the concept of stress is difficult to define. Nevertheless most agree that the experience of stress has three components: 1) the triggering event (also known as stressors); 2) the perception of the event as stressful; 3 ) the nature and the degree of reaction to the event. Lazarus and Folkman [1] defined stress as "a unique relationship between the person and the environment that is appraised by the person as taxing or exceeding his or her resources and endangering his or her well-being". Thus, the event will be stressful only if it's appraised as endangering or exceeding one's capacity. The stress has effects on one's equilibrium because of negative perception of the event. The degree to which situations in one's life are appraised as stressful is very important to assess. The impact of stressful events will be, to some degree, determined by one's perception of their stressfulness [2].

Ross, Niebling and Heckett [3] surveyed to identify major sources of stress among college students. Top five sources of stress from the study were found out to be: Change in sleeping habits, vacations/breaks, change in eating habits, increased work load and new responsibilities. Kadison and DeGeronimo [4] 
examined commonplace stress factors found on college campus such as identity development, relationships, sexuality, roommate problems, academic pressures, extracurricular demands, parental expectations, and racial and cultural differences that affect self-worth. College students, especially in the first year of the college, are faced with myriad of stressful activities. They are faced with new social norms, different peer groups, work overload, a change in lifestyle, more demands placed on time, and issues with self-control. Along with academic responsibilities, some also have work related responsibilities [5-6]. All these activities can cause stress or not - will be determined by perception of the event as being challenging or stressful. Perception of any event as stressful will also influence various aspects of well-being.

Perceived stress can affect an individual's appraisal of the situation and the way a person evaluates social support available to him/her. It not only impacts one's physical but also mental health which then leads to experiencing a vicious circle wherein events and people around are also perceived in an unfavourable manner. It is important to study which dimensions of well-being are influenced by varying levels of perceived stress among college students.

\section{Psychological well-being}

Well-being is a complex construct that concerns optimal experience and functioning. Current research on well-being has been derived from two general perspectives: the hedonic approach, which focuses on happiness and defines well-being in terms of pleasure attainment and pain avoidance; and the eudemonic approach, which focuses on meaning and self-realization and defines well-being in terms of the degree to which a person is fully functioning.

For many years, psychologists believed that well-being includes balance between positive and negative affect but then there were measurement errors in positive and negative affect such as whether to consider frequency or intensity of emotions as a measure of wellness? Another major conceptualization of wellbeing was life satisfaction, a cognitive component as opposed to happiness; an affective component to describe well-being. However, both the accounts remained incomplete of what really well-being was.

Ryff [7] synthesized past conceptualizations of well-being and proposed a theory of well-being which included even the existential and philosophical dimensions related to well-being: they are as follows:

- Self Acceptance - positive attitude toward oneself; accepting of varied aspects of self; feeling positive about past life,

- Personal Growth - feelings of continued development and effectiveness; openness to new experiences and challenges,

- Purpose in Life - possessing goals and beliefs that give direction to life; feeling life has meaning and purpose,

- Environmental Mastery - feeling competent to manage complex environment; having ability to create personally suitable living situation,

- Autonomy - feeling comfortable with self-direction; possessing internal standards; ability to resist negative social pressures from others, and

- Positive Relations with Others - warm, satisfying, and trusting relationships with others; capability of empathy and intimacy. Eudemonic well-being in this study was studied through psychological well-being.

Psychological well-being is about lives going well. It is not only experiencing good emotions but also functioning productively. Feelings of well-being are vital to the overall health of individuals, enable one to successfully overcome difficulties and achieve what one wants out of life. Well-being is associated with multiple health, job and family-related benefits. Individuals with high levels of well-being are considered to be more productive at work and are more likely to add value to their communities [8]. However, psychological well-being is compromised when negative emotions are intense and last long. It also interferes with one's ability to function effectively. Therefore, the present study has been undertaken to find out whether there is a difference in psychological well-being as a function of level of perceived stress.

Previous research has shown that level of perceived stress influences various dimensions of well-being like subjective well-being, life satisfaction, positive and negative affect [9-11]. The focus in this study was whether there is a difference in experiencing various dimensions of well-being among undergraduates as a 
function of different levels of perceived stress. If there is a significant difference then which dimensions of well-being are affected by three levels (low, moderate or high) of perceived stress.

\title{
METHODOLOGY
}

\begin{abstract}
Sample
105 college students (Males $=20$, Females $=85$ ) from Mumbai and Mumbai suburban were randomly selected to be part of the study. Their age ranged from 18- 22 years with a mean of 19.03 and SD of 1.25. Out of 105, 63 of them were from Arts, 13 were from Commerce and 29 were from Science Stream of education. After classifying these 105 participants into three groups; there were 15 in low perceived stress, 65 were into moderate perceived stress and 25 into high stress group.
\end{abstract}

The following measures were used in the study -

1. Perceived Stress Scale - It is a measure of the degree to which situations in one's life are appraised as stressful. It assesses the degree to which participants evaluate their lives as being stressful during the past month. It comprises of 14 questions with responses varying from 0 to 4 for each item and ranging from never, almost never, sometimes, fairly often and very often respectively on the basis of their occurrence during one month prior to the survey. The PSS has an internal consistency of 0.85 (Cronbach $\alpha$ co-efficient) and test-retest reliability during a short retest interval (several days) of 0.85 [12].

2. The Ryff's Scales of Psychological Well-Being - It has 18 items which consists of six subscales: (a) Positive Relations with Others (PR), Self-Acceptance (SA), Autonomy (AU), Environmental Mastery (EM), Personal Growth (PG) and Purpose in Life (PL) which are to be rated on a 6point scale that ranges from "strongly disagree" to "strongly agree". Test - retest reliability coefficients range from 0.81 to 0.85 [13].

\section{Procedure}

The measures were administered to the participants in a class room setting wherein a group of 20-25 students were instructed about the questionnaires i.e. Perceived Stress Scale and Ryff's Psychological wellbeing Scale. Their informed consent was taken. On an average, participants took 10 minutes to fill up the questionnaires. The participants were classified into three groups based on the scores on perceived stress scale. The participants who scored between 0-13 were considered as experiencing low level of perceived stress $(n=15)$, participants who scored between 14-26 were considered as experiencing moderate levels of perceived stress $(n=65)$ and participants who scored between 27-40 $(n=25)$ were considered as experiencing high level of perceived stress. The survey data obtained were analyzed descriptively as well as quantitatively.

\section{STATISTICAL ANALYSIS}

One way ANOVA (Independent Samples) with unequal cell frequencies (low $=15$, Moderate $=65$, High $=25)$ was done to find out a difference in well-being as a function of level of perceived stress. Oneway ANOVA (Independent Samples) was also calculated on six dimensions of well-being to find out which dimensions of well-being were significantly different as a function of level of perceived stress. Tukey's HSD (post hoc analysis) was also done to know which pairs of means were significantly different from each other.

\section{RESULTS}

As seen in table 1 , there was a significant difference in the mean psychological well-being scores as function of level of perceived stress $\left[\mathrm{F}_{(2,102)}=15.27, \mathrm{p}<0.001\right]$. Tukey's post hoc analysis (Refer to table 2 ) revealed that two out of three pairs of means (low-moderate and low-high) were significantly different from each other. As expected, the mean psychological well-being score was highest of participants 
experiencing low level of stress, was moderate of participants experiencing moderate level of perceived stress and was lowest of participants experiencing high level of perceived stress. Thus, as expected, the level of perceived stress significantly influenced participants' psychological well-being.

Table 1

One - way ANOVA summary of psychological well-being and its dimensions

(Independent Samples with unequal cell frequencies, $\mathrm{k}=3$ )

\begin{tabular}{|c|c|c|c|c|c|c|}
\hline & Source & SS & df & MS & $\mathbf{F}$ & $\mathbf{p}$ \\
\hline \multirow{3}{*}{$\begin{array}{l}\text { Psychological } \\
\text { well-being }\end{array}$} & Between Gps & 3820.995 & 2 & 1910.4975 & 15.76 & $<0.0001^{*}$ \\
\hline & Error & 12364.9395 & 102 & 121.2249 & & \\
\hline & Total & 15241.5619 & 104 & & & \\
\hline \multirow{3}{*}{ Autonomy } & Between Gps & 176.2936 & 2 & 88.1468 & 8.37 & $<0.001^{*}$ \\
\hline & Error & 1074.4062 & 102 & 10.5334 & & \\
\hline & Total & 1207.3333 & 104 & & & \\
\hline \multirow{3}{*}{$\begin{array}{c}\text { Environmental } \\
\text { Mastery }\end{array}$} & Between Gps & 365.5109 & 2 & 182.7554 & 21.58 & $<0.0001^{*}$ \\
\hline & Error & 863.9118 & 102 & 8.4697 & & \\
\hline & Total & 1152.9905 & 104 & & & \\
\hline \multirow{3}{*}{$\begin{array}{c}\text { Positive } \\
\text { Relations with } \\
\text { Others }\end{array}$} & Between Gps & 102.7789 & 2 & 51.3894 & 3.99 & $<0.02^{*}$ \\
\hline & Error & 1314.5887 & 102 & 12.8881 & & \\
\hline & Total & 1416.7619 & 104 & & & \\
\hline \multirow{3}{*}{ Self-Acceptance } & Between Gps & 136.2202 & 2 & 68.1101 & 5.63 & $0.005^{*}$ \\
\hline & Error & 1233.5487 & 102 & 12.0936 & & \\
\hline & Total & 1334.1333 & 104 & & & \\
\hline \multirow{3}{*}{ Personal growth } & Between Gps & 41.1467 & 2 & 20.5734 & 2.73 & $<0.07, \mathrm{NS}$ \\
\hline & Error & 767.7846 & 102 & 7.5273 & & \\
\hline & Total & 798.2476 & 104 & & & \\
\hline \multirow{3}{*}{ Purpose in Life } & Between Gps & 9.9173 & 2 & 4.9586 & 0.34 & $0.71, \mathrm{NS}$ \\
\hline & Error & 1492.0615 & 102 & 14.6281 & & \\
\hline & Total & 1499.6571 & 104 & & & \\
\hline
\end{tabular}

Table 2

Tukey HSD of psychological well-being

\begin{tabular}{|c|c|c|c|}
\hline $\mathbf{N}=\mathbf{1 0 5}$ & Low $\mathbf{( n = 1 5 )}$ & Moderate $(\mathbf{n}=\mathbf{6 5})$ & High $(\mathbf{n}=\mathbf{2 5})$ \\
\hline Low $(100.47)$ & --- & $10.58^{* *}$ & $17.51^{\text {** }}$ \\
\hline Moderate (89.89) & --- & -- & 6.93 \\
\hline High $(82.96)$ & --- & --- & -- \\
\hline
\end{tabular}

$\operatorname{HSD}(0.05)=7.47, \operatorname{HSD}(0.01)=9.35,{ }^{*} \mathrm{p}<0.05,{ }^{* *} \mathrm{p}<0.01$

Table 3

Tukey HSD of Autonomy

\begin{tabular}{|c|c|c|c|}
\hline $\mathbf{N}=\mathbf{1 0 5}$ & Low $\mathbf{( n = 1 5 )}$ & Moderate $\mathbf{( n = 6 5 )}$ & High $(\mathbf{n = 2 5})$ \\
\hline Low (17.40) & --- & $6.82^{* *}$ & $3.44^{* *}$ \\
\hline Moderate (14.31) & --- & --- & 0.35 \\
\hline High (13.96) & --- & --- & --- \\
\hline
\end{tabular}

$\operatorname{HSD}(0.05)=2.20, \operatorname{HSD}(0.01)=2.76,{ }^{*} \mathrm{p}<0.05,{ }^{* *} \mathrm{p}<0.01$ 
The table 1 showed the one way ANOVA summary of autonomy dimension of psychological well-being too. Autonomy refers to being self-reliant, no need to conform and not worrying much about what others think. There was a significant difference in autonomy as a function of level of perceived stress $\left[\mathrm{F}_{(2,102)}=\right.$ 8.37, $\mathrm{p}<0.001]$. Table 3 showed the Tukey's post hoc analysis for autonomy dimension. Two out of three pairs of means showed a significant difference (low-high, low-moderate). It showed that the participants' experiencing low level of perceived stress were highest on autonomy, followed by those who were experiencing moderate level of perceived stress and participants with high level of perceived stress reported to be lowest on autonomy dimension of psychological well-being.

Table 4

Tukey HSD of Environmental Mastery

\begin{tabular}{|c|c|c|c|}
\hline$N=105$ & Low $(n=15)$ & Moderate $(n=65)$ & High $(n=25)$ \\
\hline Low (17.73) & --- & $2.76^{\star *}$ & $5.45^{\star *}$ \\
\hline Moderate (14.97) & --- & --- & $2.69^{* *}$ \\
\hline High (12.28) & --- & --- & --- \\
\hline
\end{tabular}

As seen in table 1, there was a significant difference on environmental mastery as a function of perceived stress $\left[\mathrm{F}_{(2,102)}=21.58, \mathrm{p}<0.001\right]$. People high on environmental mastery are effectively able to meet the demands of life, adjust to problems and are not overwhelmed by stress. Whereas people with low level of environmental mastery are unsatisfied, feel that they lack the resources to cope and are frequently stressed. Table 4 showed the post hoc analysis which revealed that all the three pairs of means were significantly different from each other. Thus, this clearly indicated that participants with low level of perceived stress reported to be highest on environmental mastery, participants with moderate level of perceived stress were moderate on environmental mastery and participants with high level of perceived stress were lowest on environmental mastery.

The findings obtained in this study were also supported by the past research. Chang [14] studied the relationship between stress, and dimensions of psychological well-being in college students. The results indicated that stress influenced three out of six dimensions of psychological well-being, namely, autonomy, environmental mastery, and purpose in life. However, this relationship in his study was mediated by socially prescribed perfectionism.

Table 5

Tukey HSD for Positive Relations with Others

\begin{tabular}{|c|c|c|c|}
\hline $\mathbf{N ~ = ~ 1 0 5 ~}$ & Low ( $\mathbf{n = 1 5 )}$ & Moderate $\mathbf{( n = 6 5 )}$ & High (n=25) \\
\hline Low (14.07) & --- & 0.59 & $2.75^{*}$ \\
\hline Moderate (13.48) & --- & --- & 2.16 \\
\hline High (11.32) & --- & --- & -- \\
\hline
\end{tabular}

$\operatorname{HSD}(0.05)=2.44, \operatorname{HSD}(0.01)=3.05,{ }^{*} \mathrm{p}<0.05$

Table 1also showed the one way ANOVA summary of 'Positive Relations with Others' dimension of psychological well-being. There was a significant difference on this dimension as a function of perceived stress $\left[F_{(2,102)}=3.99, p<0.02\right]$. Individuals high on positive relations with others feel connected, respected and well-loved. They can share aspects of themselves, experience intimacy, and usually feel secure in their relations. People low on this aspect, feel unappreciated, disrespected, disconnected, or misunderstood. They tend to feel alone or distant from others. The post hoc analysis as seen in table 5 showed that only one pair of mean (low-high) was statistically significant out of three pairs of means. That showed that participants with low level of perceived stress were significantly higher on positive relations with others as compared to participants with high level of perceived stress. 
Table 6

Tukey HSD of self-acceptance

\begin{tabular}{|c|c|c|c|}
\hline $\mathbf{N ~ = ~ 1 0 5 ~}$ & Low ( $\mathbf{n = 1 5 )}$ & Moderate $\mathbf{( n = 6 5 )}$ & High (n=25) \\
\hline Low (17.27) & --- & 2.2 & $3.27^{\text {** }}$ \\
\hline Moderate (15.07) & --- & -- & 1.07 \\
\hline High (14.00) & --- & --- & -- \\
\hline \multicolumn{2}{|c|}{ HSD $(0.05)=2.36$, HSD $(0.01)=2.95,{ }^{*} \mathrm{p}<0.05,{ }^{* *} \mathrm{p}<0.01$} \\
\end{tabular}

Table 1 showed that there was a significant difference on self acceptance as a function of perceived stress $[F(2,102)=5.63, p<0.005]$. Self acceptance refers to the degree to which one has positive attitudes about oneself. Participants with high self acceptance are pleased with who they are and accept good as well as bad aspects of oneself. In contrast, people low on this dimension, are often self-critical, and confused about their identity. Table 6 which showed the post hoc analysis revealed that participants' with low perceived stress were significantly higher on self acceptance compared to participants' with high perceived stress. There was no significant difference on self acceptance in other two pairs (low-moderate and moderatehigh).

Table 1 showed the one way ANOVA summary of personal growth dimension of psychological wellbeing. There was not a statistically significant difference on personal growth as a function of level of perceived stress $\left[\mathrm{F}_{(2,102)}=2.73\right.$, NS]. Individuals with high levels of personal growth see themselves as changing in a positive direction, moving toward their potential, becoming more mature, increasing their self-knowledge, and learning new skills. Individuals with low in personal growth feel no sense of change or development, often feel bored and uninterested in life, and lack a sense of improvement over time. Participants in this study did not show a significant difference on personal growth as a function of perceived stress. This implied that irrespective of level of perceived stress experienced, participants can continue to grow in life which can enhance their psychological well-being.

Table 1 showed the one way ANOVA summery of 'purpose in life' dimension of psychological well-being. As seen in the table, there was no significant difference in purpose in life as a function of level of perceived stress $\left[F_{(2,102)}=0.34, \mathrm{NS}\right]$. Individuals with high sense of purpose in life see their life as having meaning, they work to make a difference in the world, and often feel connected to ideas or social movements larger than themselves. Individuals with low in purpose in life do not feel their life makes sense, and attribute no higher meaning or value to life. In the present study, participants did not show any significant difference on purpose in life as a function of stress. Thus, irrespective of level of perceived stress, participants' who can maintain high purpose in life can make a difference in society and can experience high value in living one's life which will in turn help them experience enhanced psychological well-being.

\section{DISCUSSION}

These findings were also supported in a study by some researchers [15]. They showed that participants in their study who had high purpose in life showed improved coping when faced with a challenge or stress. The participants did not blow daily hassles and stress out of proportion and took preventive health measures as they found their life meaningful. Individuals with high purpose in life were not only cognizant of what was worthwhile but were also able to keep frustrations and annoyances in perspective. Thus, irrespective of levels of stress, if one can develop meaning in one's existence, one can enhance one's psychological well-being.

The past research supported the present findings. In one study [16], a significant negative correlation was found between stress and psychological well being among female adolescents. It was observed that there is high prevalence of mental health disorders and stress among school going females so it is necessary to teach them stress management techniques to help them enhance well being in all facets of their life. If the college students can be coached to focus on finding meaning in one's existence and developing one's 
strengths and skills even in the midst of challenges; their well-being can be enhanced irrespective of level of stress experienced.

Cammata and Nagoshi [17] investigated the role of stress on depression and alcohol use. The results showed that college students who experienced high stress also reported high depression due to high stress which further made them abuse alcohol. This showed that the relationship between stress and alcohol problems was mediated by depression. However, if these students in spite of experiencing high stress were guided to explore meaning in life and find areas of their life that they can grow; they could have creatively dealt in with their daily stressors instead of succumbing to substance abuse.

Past studies have shown association between stress and well-being. A study investigated the status of antibody after meningitis vaccination as a function of perceived stress and general health. The participants who perceived high stress were found to be having low antibodies after vaccination. Those who scored low on general health i.e those who reported high anxiety or lack of sleep or social dysfunction - were associated with low antibody status after meningitis vaccination. Thus, this study demonstrated the influence of stress and general health on antibody status after vaccination [18].

The results of a study by Harris, Cumming and Campbell [19] revealed that high perceived workplace stress was found to be single most significant predictor of psychological well-being and satisfaction with life among allied health professionals consisting of social workers, psychologists, occupational therapists, physiotherapists, speech pathologists, and a small number of other allied health professionals.

Garcia, Al Nima, and Kjell [20] studied individuals categorised as self-fulfilling (having high positive affect and low negative affect) and found that they tended to score higher on the psychological well-being dimensions: positive relations, environmental mastery, self-acceptance, autonomy, personal growth, and purpose in life. In addition to this finding, individuals categorised as self-fulfilling also tended to report higher levels of harmony in life. Thus, it can be implied that people who are high on positive affect and low on negative affect that is experiencing more joy and less stress experience well-being in all its dimensions.

Kozka and Przybyla-Basista [21] studied the role of perceived stress on parents' well-being. Parenting is a burden as well as a challenge when having children with a genetic abnormality like Down syndrome. The study results revealed that in spite of reporting high level of stress in the environment, the effect of perceived stress got weakened among parents who showed high resilience and adaptive functioning (ego resilience) and these parents reported more happiness and satisfaction in spite of being the parents with Down syndrome children. The psychological well-being of parents who perceived their parenting as satisfying and happy was much enhanced compared to parents who perceived their parenting as a burden or a challenge or ordinary. That is, parents who saw their parenting as meaningful or satisfying could still experience well-being in spite of having children with abnormality. This was also seen in this study wherein participants' well-being was not statistically significantly different as a function of level of stress in two of the dimensions (purpose in life and personal growth).

\section{Limitations}

Four out of six dimensions (autonomy, self-acceptance, environmental mastery, and positive relations with others) were significantly different as a function of level of perceived stress. However, more mediating variables like self-efficacy, self-regulation, perfectionism or emotional regulation skills affecting the link between psychological well-being and stress need to be researched to enhance the understanding of studied variables. The sample consisted of urban youth only; to increase the impact of the study, rural population also can be included.

\section{CONCLUSIONS}

The present study is an attempt to contribute to our understanding of perceived stress and its relationship with psychological well-being among college students. Results indicated that psychological well-being was found to be significantly different as a function of level of perceived stress. However, purpose in life and personal growth dimensions of psychological well-being were not significantly different as a function of stress levels. This study can be applied in college counselling for positive youth development where the 
mental health counsellor of the college can assess the perceived stress levels of the youth and can help them develop purpose in life and focus on personal growth which will enhance their ability to recover from stress and enhance their psychological well-being.

\section{REFERENCES}

1. Lazarus RS, Folkman S. Coping and adaptation. The handbook of behavioral medicine. 1984:282-325.

2. Wolpe J, Lazarus AA. Behavior therapy techniques: A guide to the treatment of neuroses. American Psychiatric Press ; 1966.

3. Ross SE, Niebling BC, Heckert TM. Sources of stress among college students. Soc Psychol 1999;61(5):841-6.

4. Kadison RD. The mental health crisis: What colleges must do. The Chronicle of Higher Education 2004 ;51(16):B20.

5. Guo YJ, Wang SC, Johnson V, Diaz M. College students stress under the current economic downturn. College Stud J 2011;45(3):168-73.

6. Singh A, Upadhyay A. Age and sex differences in academic stress among college students. Soc Sci Int 2008;24(1):78-88.

7. Ryff $\mathrm{CD}$. Happiness is everything, or is it? Explorations on the meaning of psychological well-being. $\mathrm{J}$ Personal Soc Psychol 1989;57(6):1069-76.

8. Huppert FA, So TT. Flourishing across Europe: Application of a new conceptual framework for defining well-being. Soc Indicators Res 2013;110(3):837-61.

9. Spada MM, Nikčević AV, Moneta GB, Wells A. Metacognition, perceived stress, and negative emotion. Personal Individ Diff 2008;44(5):1172-81.

10. Atanes AC, Andreoni S, Hirayama MS, Montero-Marin J, Barros VV, Ronzani TM, Kozasa EH, Soler J, Cebolla A, Garcia-Campayo J, Demarzo MM. Mindfulness, perceived stress, and subjective well-being: a correlational study in primary care health professionals. BMC Complement Alt Med 2015;15(1):303.

11. Myers JE, Sweeney TJ, Witmer JM. The wheel of wellness counseling for wellness: A holistic model for treatment planning. J Couns Dev 2000;78(3):251-66.

12. Cohen S, Kamarck T, Mermelstein R. Perceived stress scale. Measuring stress: A guide for health and social scientists. 1994.

13. Ryff CD. Psychological well-being in adult life. Curr Dir Psychol Sci 1995;4(4):99-104.

14. Chang EC. Perfectionism and Dimensions of Psychological Well-Being in a college Student Sample: A test of a stress-Mediation Model. J Soc Clin Psychol 2006;25(9):1001-22.

15. Freeborn DK, Hooker RS, Pope CR. Satisfaction and well-being of primary care providers in managed care. Evaln Health Profess 2002;25(2):239-54.

16. Chida Y, Steptoe A. Positive psychological well-being and mortality: a quantitative review of prospective observational studies. Psychosom Med 2008;70(7):741-56.

17. Camatta CD, Nagoshi CT. Stress, depression, irrational beliefs, and alcohol use and problems in a college student sample. Alcohol Clin Exp Res 1995;19(1):142-6.

18. Burns VE, Drayson M, Ring C, Carroll D. Perceived stress and psychological well-being are associated with antibody status after meningitis $C$ conjugate vaccination. Psychosom Med 2002;64(6):963-70.

19. Røysamb E, Tambs K, Reichborn-Kjennerud T, Neale MC, Harris JR. Happiness and health: environmental and genetic contributions to the relationship between subjective well-being, perceived health, and somatic illness. J Personal Soc Psychol 2003;85(6):1136-44.

20. Garcia D, Al Nima A, Kjell ON. The affective profiles, psychological well-being, and harmony: environmental mastery and self-acceptance predict the sense of a harmonious life. Peer J 2014;2:e259.

21. Kózka A, Przybyła-Basista H. The Relationships between Perceived Stress and Psychological Well-being Among Mothers and Fathers of Children with Down Syndrome. Stanisław Juszczyk 2015;10:285-90.

$$
\begin{aligned}
& * * * * * * * * * * * * * * * * * * * * \\
& \text { Acknowledgements }- \text { Nil } \\
& \text { Source of Funding }- \text { Nil } \\
& \text { Conflict of Interest }- \text { Nil }
\end{aligned}
$$

